feature of the condition; one patient asked if her daughter was wearing a new dress, even though the patient had been with her when she bought it the day before.

While episodes of prolonged amnesia occurring as a response to stress are often construed as being hysterical, this organic syndrome is quite unlike so-called hysterical amnesia, in which the patient is unaware of his own identity and of his address and is often incapable of answering any questions about himself or his past life. In transient global amnesia, by contrast, memory for events in the remote past and awareness of identity usually remain intact even during the attack, but the patient knows that his memory is defective and is incapable of repeating within a few seconds or minutes a test phrase offered to him. These episodes commonly occur in middle-aged or elderly patients who show evidence of mild hypertension or atherosclerosis, they have been described as coming on after exertion or prolonged exposure to cold, and recovery is almost invariably complete within a few hours; all this strongly suggests that the syndrome is due to transient cerebral ischaemia. Recent clinical and experimental evidence has underlined the importance of the mamillaryhippocampal complex in memory function, and Bolwig ${ }^{5}$ has suggested that this syndrome is probably the result of transient ischaemia in the hippocampal region of one or other temporal lobe-a view which is now widely held. In the typical case transient amnesia alone is rarely, if ever, an indication for specialized neuroradiological investigations, including angiography, and since recovery within a few hours can be confidently predicted no specific treatment other than reassurance or sedation is needed. The disorder is probably much more common than is generally recognized. It is alarming both to the patient and to his relatives, but the prognosis appears to be uniformly favourable.

\section{Elusive Salmonellae}

Organisms of the salmonella group are widely distributed throughout nature, and it is scarcely surprising that most primary agricultural products are contaminated with them. Outbreaks of food-poisoning, or less frequently of enteric fever, can often be traced to eating contaminated food. Consequently much of the work of public health laboratories in the United Kingdom and other countries is devoted to the examination of foods and food products, as well as of animal and human excreta, for the presence of salmonellae. With so much effort being expended in the chase it is desirable both that the bag should be a good one and that different laboratories should show consistency in their results.

Results were compared from various laboratories of isolating salmonellae from samples of pig faeces and minced meat which were either naturally contaminated or had been artificially contaminated with Salmonella utrecht. ${ }^{1}$ The laboratories taking part in this strenuous technical Olympic were situated in eight countries in Western Europe, including Britain, and each employed its own routine techniques. It was found that all were equally successful at isolating salmonellae so long as there was no large competing flora, but, as soon as the non-salmonella bacterial population increased, results from the different laboratories became much more inconsistent. This particularly applied to the isolation of salmonellae from artificially contaminated minced meat.
An earlier comparison ${ }^{2}$ of results of attempted salmonella isolation from minced meat was undertaken by five different laboratories in the Netherlands. Two of the five obtained lower numbers of positive isolations than the remaining three. Though in the earlier part of the investigation the different laboratories used the techniques of isolation to which they were accustomed, later a standardized technique was followed in all laboratories. Despite this uniformity there was no evidence that the two laboratories whose results were below standard showed any improvement. Even those laboratories judged comparatively efficient failed to identify appreciably more than half the positive samples.

Several factors may contribute to discrepancies in the results of such trials. For instance, in the circumstances of natural contamination salmonellae are not evenly distributed

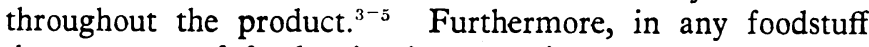
the presence of food-poisoning organisms may be obscured by that of other germs. ${ }^{167}$ Cold storage of the foodstuff also increases the difficulty of isolating salmonellae either by lowering their numbers in relation to the competing microflora $^{1}$ or by subjecting them to low-temperature metabolic injury such as has been described in connexion with other germs. $^{8}$ It is to compensate for these difficulties that various techniques of treating inocula containing a mixed flora and including salmonellae have been described. ${ }^{9-11}$ The enrichment medium devised by F. Rappaport, N. Konforti, and B. Navon ${ }^{12}$ has been subjected to careful trial ${ }^{13-15}$ and seems to offer considerable advantages. The biodynamics of salmonella enrichment are of exceptional interest and have been carefully studied by J. E. Jameson, ${ }^{16}{ }^{17}$ from whose observations the value of secondary enrichment is clear.

In view of all these difficulties one may wonder why foodstuffs cannot be examined in the same way as water supplies, the presence of the coli-aerogenes group of bacteria being accepted as an indication of faecal pollution. Unfortunately the presence of faecal coliform organisms is not necessarily directly related to the presence of organisms of the salmonella group. 1819

In a field full of the risks of discrepancy, sampling and bacteriological techniques are two variables which lend themselves most easily to international standardization. But E. H. Kampelmacher's observations ${ }^{2}$ indicate that factors making for diverse results exist which are not purely technical or the result of heterogeneous distribution of salmonella in foods. While it is to be hoped that local and international agreement may be reached on these matters, it may be a relief to microbiologists in an automated age to know that here, as in other areas of their art, there is in the end no substitute for experience.

\footnotetext{
Working Group, Comparative Studies on Salmonella-isolation in Eight European Laboratories, in press.

2 Kampelmacher, E. H., Zbl. Bakt., I. Abt. Orig., 1967, 204, 100.

s Adam, W., Zbl. Bakt., I. Abt. Orig., 1956, 167, 224.

- Lorenz, W., Wien. tierarztl. Mschr., 1961, 48, 448.

Semple, A. B., Graham, A. J., and Dutton, E. M., Med. Offr, 1961, $105,59$.

- Mossel, D. A. A., Zbl. Bakt., I. Abt. Orig., 1958, 166, 421.

, Thatcher, F. S., Food Technol. Champaign., 1958, 12, 117.

- Postgate, J. R., and Hunter, J. R., f. appl. Bact., 1963, 26, 405.

- Georgala, D. L., and Boothroyd, M., f. appl. Bact., 1965, 28, 206.

10 Jameson, J. E., f. Hyg. (Lond.), 1961, 59, 1.

11 Taylor, J., Ass. clin. Pathol. Broadsheet No. 58, 1967. London.

12 Rappaport, F., Konforti, N., and Navon, B., ł. clin. Path., 1956, 9, 261.

13 Iveson, J. B., Kovacs, N., and Lawrie, W., f. clin. Path., 1964, 17, 75.

14 Anderson, K., and Kennedy, H., f. clin. Path., 1965, 18, 747.

15 Iveson, J. B., and Kovacs, N., f. clin. Path., 1967, 20, 290.

16 Jameson, J. E., f. Hyg. (Lond.), 1962, 60, 193.

17 Jameson, J. E., $\%$ appl. Bact., 1963, 26, 112.

18 Hobbs, B. C., and Wilson, J. G., Mth. Bull. Minist. Hlth Lab. Serv., $1959,18,198$.

19 Thatcher, F. S., and Montford, J., Canad. F. publ. Hlth, 1962, 53, 61.
} 